\title{
Development and validation of a coupled model system in the Baltic region-BALTIMOS
}

\author{
Daniela Jacob
}

Published online: 17 October 2014

(C) Springer-Verlag Wien 2014

During the last decades, ongoing climatic change in the region of the Baltic Sea became evident from hydro-meteorological observations. This raised concerns about the future of the Baltic Sea and its surrounding catchment and asked for an in-depth understanding of the processes, which determine the climate of the region. Within the Global Energy and Water Cycle Experiment (GEWEX) - one of the projects of the World Climate Research Programme (WCRP) - one of the continental-scale experiments (CSEs) addressed the Baltic Sea region: the Baltic Sea Experiment (BALTEX).

The major objectives of BALTEX were to determine the water and energy budgets for the Baltic Sea and its catchment area, to identify and to understand the processes, which are influencing the water and energy cycles, and to create a base for the simulation of the water and energy cycles under climate change conditions.

Besides ongoing process studies, numerical models with finer spatial resolution were developed separately for the atmosphere, the Baltic Sea, and hydrological processes during the last years in BALTEX. The individual models could be applied successfully as demonstrated by many comparisons with observations. Because of their fine resolution and resulting detailed information, these models can be used for studies of climate and climate change in the Baltic Sea region.

However, not all aspects and branches of the water and energy cycles could be simulated satisfactorily so far. For example, an accurate estimate of the annual cycles of precipitation and evaporation over the Baltic Sea, important quantities of the fresh water budget, is missing. One reason is that parts of the water and energy cycles were investigated separately in the involved scientific

D. Jacob $(\bowtie)$

Climate Service Center 2.0 (CS2.0), Helmholtz-Zentrum Geesthacht, Fischertwiete 1, 20095 Hamburg, Germany

e-mail: daniela.jacob@hzg.de disciplines, e.g. the atmospheric water balance in the field of meteorology, evaporation from the Baltic Sea in the field of oceanography, and river runoff in the field of hydrology.

In this special issue, the results from a research project financed by the German Ministry of Research within the national research program DEKLIM are presented in a series of nine papers. They describe the coupled model system for the Baltic Sea region, called BALTEX Integral Model System (BALTIMOS), together with a comprehensive validation using data from about one decade. Validation is a necessary condition in order to achieve reliable estimates of the water and energy budgets for the Baltic Sea area not only for present climate conditions but also for future large-scale climate changes.

Model validation focussed primarily on water cycle components. A multitude of observations ranging from in situ measurements to surface- and satellite-based measurements were applied. Observations made during BALTEX/BRIDGE and its intensive measurement campaigns have been used.

The development of regional coupled modeling systems, like BALTIMOS for the Baltic Sea, is still an important and ongoing task. During the Third International Regional-scale Workshop on 21st Century Challenges in Regional Climate modeling, which took place in June 2014 in Lund, Sweden, an entire session was devoted to regional coupled atmosphereocean modeling. In the meantime, a handful of regional coupled modeling systems are available worldwide, but only very few are applied to the Baltic Sea region and their performances are still not fully satisfactory. The careful validation of such modeling systems under today's climatic conditions and against a variety of independent observational datasets is a major trust building step toward projections of possible future changes of the climate.

During the last GEWEX conference, July 2014, it again was stated that there are still limitations in our ability to 
understand and model change in extreme weather events for todays climate and that there is an increasing demand from society for information about possible changes of such events in the future. Global efforts are ongoing in the scientific community, which can more and more benefit from the
GEWEX CSEs like BALTEX and the knowledge gained in BALTIMOS.

Unfortunately, there has been a strong delay in finalizing this special issue for which I beg you to accept my sincere apologies. 